\title{
Transparency in Project Management - from Traditional to Agile
}

\author{
Jan Betta \\ Computer Science and Management \\ Wroclaw University of Science and Technology \\ Wroclaw, Poland \\ jan.betta@pwr.edu.pl
}

\author{
Liudmila Boronina* \\ Institute of Public Administration and Entrepreneurship \\ Ural Federal University \\ Ekaterinburg, Russia \\ 1.n.boronina@urfu.ru
}

\begin{abstract}
The article provides a comparative analysis of the transparency phenomenon in different project management methodologies. The key issues of the study are: understanding of transparency in different theoretical paradigms, universal and specific characteristics of transparency, models and types of transparency depending on the type of project, scope of implementation, the regime of accountability, sources of funding, methodology of project management. The research analysis was carried out using the methods of document analysis, secondary data analysis, data integration, benchmarking and case-method. It's has been established that transparency is a necessary condition and tool for project stakeholders' relationship management. The dynamics of the development of the theory and practice of project management - from the classical project management (Project management body of knowledge PMBOK) to the family of flexible iterative-incremental methods of project and product management (Agile) changes the modality of transparency and the processes of its operationalization in the logic of possible and mandatory.
\end{abstract}

Keywords-Transparency; Project management; Stakeholder relationship management; Methodologies of PMBOK; Agile

\section{INTRODUCTION}

Project management is a relevant science that doesn't have universal solutions and secure foundations. A lot of effective management paradigms, methods and standards have been created during the existence of project management, starting with the classical project management (PM), represented primarily by the PMBOK and ending with the family of flexible iterative-incremental Agile methods (Scrum, Lean, Kanban, Six Sigma, PRINCE2). Comparative analysis of methodological approaches in discursive practices is introspective and, as a rule, debatable-rhetorical, articulated by the question "which approach is better?" Project selfknowledge, focused mainly on the identification of the degree of standardization, formalization, structuring, specification, self-sufficiency and adaptability of project methodological approaches leaves without research attention two essential differences associated with the subject and organization of project management. The first demarcation line lies in the differentiation plane of the control object on Project Management Processes and Project Life Cycle. Processes of project management reflect the approach to project management in general, in the aggregate of high-level processes and techniques used regardless of the industry affiliation of projects. So PMBOK is constructed around 5 groups of management processes and 9 areas of knowledge. Flexible Agile technologies are focused on a specific implementation of management processes in the format of life cycle management of a single project. Because of this, they are more adaptive, less formalized and from the point of view of the traditional approach allow the exclusion or absence of an explicit description of a number of processes. Another difference is the level of project management (PM) organization. Many PM practices are divided into Project Management, Program Management and Portfolio Management. The degree of influence of Agile is gradually reduced in the process of consecutive transition from one level to another, but is more consistent with Portfolio Management [1], optimally implementing in the conditions of large enterprises the transfer of Portfolio Management to the project level, introducing flexible, "empirical" project management processes, such as a Scrum. It can be assumed that different methodologies of the PM have different conceptual views and ways of transparency operationalizing.

\section{BACKGROUND}

In the operational aspect, transparency supposes the availability, speed, high degree of structuring of information and the presence of feedback and information exchange in the interaction in the imperative of interactivity. At the same time, the author's interpretation of transparency is different and dependent on the disciplinary context, the commitment of researchers to a particular theoretical paradigm. In postmodern philosophy, transparency is a fundamental characteristic of the modern information society. Postmodern assessments of transparency are not unambiguous. On the one hand, transparency, as total openness of information, is a manifestation of the instrumental form of freedom [2] on the other - it disrupts the distance between privacy and publicity, enhances the opportunities for social design of supervision in various spheres [3]. In modern sociological concepts of social capital [4], transparency is seen as a phenomenon that increases the degree of trust of actors in the system of social contacts and relations. In management theories, transparency, as "information disclosure" [5], acts as an element of planning and accountability, in public administration - is further associated with the function of control over corruption processes. In management theories, transparency, as "information disclosure" [5], acts as an element of planning and accountability, public administration - is further associated with the function of control over corruption processes. In 
management, transparency is a multidimensional component. Hood C. and Heald D. [5] allocate 5 pairs of transparency's types, depending on the time, method and direction of "information disclosure: ascending (openness of management information for subordinates) and descending (openness and clarity of the activities of employees for managers); external (availability of information for external partners of organization) and internal (transparency of decisions for all members of organization); transparency of events and processes (transparency of information about specific events and processes in achieving corporate goals); nominal (accessibility of information for stakeholders), and effective transparency (accessibility and clarity of information for stakeholders) [6]; limited (with preservation of trade secrets in business projects) and expanded (public-private partnership projects involving public control) [2]. How are the models and types of transparency differentiated depending on the methodology of project management?

\section{TRAnsParency In TRAditional PROJECT MANAGEMENT APPROACH}

The most obvious way to make a project more manageable is to break the process of its execution into successive stages. It is on this linear structure that the traditional project management is based. The classical sphere of application of the classical approach continues to be construction and engineering projects, in which the content of the project remains practically unchanged throughout the entire project. The expansion of traditional PM technologies to various spheres of public life, the active development of flexible project methodologies led to a significant transformation of the classical PM. And, above all, this refers to the phenomenon of transparency. In the fifth version of the PMBOK standard (2013), the tenth knowledge area "Project stakeholder management" [7] appears, which is iterative, is an integral part of all project process groups, implemented at all stages of the project life cycle. The methods and tools stated in the standard reflect the mechanisms of ascending, descending, external and internal transparency. Transparency of communications is ensured by accessibility, a high degree of structuring of information and formalization of interaction with stakeholders. Each stage of the project is accompanied by a specific set of documents for stakeholders, as well as an appropriate strategy for effective stakeholder management, based on an analysis of their needs, interests and potential impact on project success. The ways of operationalization of transparency at all stages of work with stakeholders (identification, stakeholder management planning, involvement management and monitoring) are rather traditional: expert surveys, meetings, communication, conclusion of agreements, notifications of stakeholders, formal and informal project reports, presentations and project records, documentation of lessons learned. Whether these methods are nominal or effective, practice shows.

Case 1 [8]

Company AXELOS, which owns a portfolio of best practices and methodologies of PM, released a study of the current situation in the market of project management in the world. The main research topics: challenges faced by project managers; preferred approaches and methods of PM, modern problems of project PM. The results of the study showed that "project managers face the same challenges as the rest of the business: reducing budgets, requirements for creating greater value, increasing productivity and the number of results" [8]. The most used approaches were PRINCE2 (60\%) and PMBoK (48\%), as well as ITIL (42\%). Less than $20 \%$ of respondents noted that their organizations are constantly improving the monitoring and feedback processes. The main factors of project failures: ambitious timing (59\%), changing requirements and expectations of stakeholders (56\%); lack of an assessment of previous experience, including ones of stakeholders $(48 \%)$; inefficient communications, incorrectly formed project team $(50 \%)$ [8].

\section{Transparency As Essential Principle Of Agile PM APPROACH}

\section{A. Transparency in Leading Agile PM Methodologies}

As it has been shown in the previous section, in traditional methodologies transparency appears, but it is considered as a second order value. It is recommended but not required. There are many examples of real cases of resistance to changes, due to the transparency insufficiency [9], [10]. The situation of transparency sub-estimation evaluated gradually, little by little, from the beginning of PM, until the publication of Manifesto of Agile Software Development [11], considered as the birth of Agile approach to PM, really revolutionary. The Manifesto consists of four demands: individuals and interactions over processes and tools; working software (product) over extensive documentation; customer collaboration over contract negotiation; responding to change over following a plan.

During about twenty last years, several methodologies satisfying Agile Manifesto requirements appeared and are implemented. Let's show the role of transparency in them. The Scrum methodology was formulated in 1995 by Ken Schwaber and Jeff Sutherland [12]. Scrum is a framework designed to overcome complex adaptive problems and to deliver a product with the greatest possible value for the customer.

Scrum is based on empiricism, which builds [12]: transparency within each process; inspection to detect problems in the project; adaptation to changes. Transparency means clearness of the Scrum processes. Process should be defined in such way that all project stakeholders could understand its run, so, the work they must done. It requires an elaboration of clear standards and a common language of communication, limiting the arbitrariness of notions understanding by Scrum Team members.

Other important elements of Scrum are Values [12]; one of them is Openness. It is related to the openness to criticism, people and changes, permanent education and experiences acquisition, as well as to feedback information so, results of inspection and necessary adaptation. Openness contributes a lot in transparency.

Let's mention two other agile methodologies, commonly used. Extreme Programming (XP) [13] is an agile methodology, based on four principles. First of them is communication (transparency). Crystal Methodologies [14]; its key tenets 
include teamwork, transparency, simplicity, product and autoadaptation

\section{B. Bibliographical Cases of Transparency in Agile Approach}

Case 2 [15]

The study, basing on systematic literature review of 118 primary studies, deals with global software development (GSD) project management. In the paper [15] the factors related to the successful project management in GSD were identified and verified in the real-world practice, and map to 10 project management knowledge areas of PMBOK. Among 18 factors of successful GSD projects management, communication (transparency) 54\%, is the third most frequently mentioned success factor in this study. Because of the development sites are spread across geographical boundaries, communication between different sites is very important. Communication can generally be categorized as two types: synchronous and asynchronous. Synchronous communication consists in face-toface meetings and discussion with team members and customers. Because GSD is different from collocated development due to the geographical separation of teams, communicating face-to-face is not possible. A lack of face-toface meeting scan affect seriously project management challenges. Concluding, communication capabilities have an important impact on the results of GSD projects [15].

\section{Case 3 [16]}

A literature research was performed on the most used Project Management (PM) methodologies worldwide to identify the most successful ones. Twelve methodologies were taken into consideration. The study based on iterative processes, cross-functional teams, face-to-face communication with stakeholders, constant reports on team member productivity, and quality focus by utilizing measurement tools and techniques. This method has given the following results: $92 \%$ of those surveyed indicate agile management elements improving the ability to manage changing priorities; $85 \%$ indicate agile management tools improve project visibility (transparency); $77 \%$ indicate using agile tools enhanced software quality. Agile is one of three the best methodologies, with leading role of transparency as a factor of success.

\section{Case 4 [17]}

The paper focuses on participation and transparency as the main objectives for the results of Enterprise 2.0 platform, positively influencing on the interaction transparency, enabling trust and cooperation capabilities. The answer on the basic question "What are the key methods in project management of Enterprise 2.0 platform?" is given by the authors [17] as a list of 9 implemented tools. Question itself and the answers show a high importance related to transparency in projects of Enterprise 2.0 platform.

\section{RESULTS}

Transparency is a universal characteristic of project development and implementation processes. At the same time, the ways of operationalizing transparency in different PM methodologies are different from each other, as well as (by analogy with various paradigms of classical sociology) "compulsory sociology" by E. Durkheim and "understanding sociology" by M. Weber. In the classical model of the PM, transparency is reduced, mainly, to the function of informing all stakeholders using traditional forms of management communication (meetings, notices, formal reports on the project). Modern PM models, laying the transparency on the axiological level, go beyond the general understanding of transparency as "information disclosure", expand the information support of the project to the tools that contribute to the understanding of all management processes and procedures, form a two-way flow of information and, as a consequence, personal and institutional trust between all project participants.

\section{CONCLUSION}

Finally, there is no business world without projects, there is no projects success without transparency.

\section{REFERENCES}

[1] K. Thompson, "Agile PMO," Agile Russia [Web resource] Retrieved from URL: http://agilerussia.ru/practices/agile-pmo/.

[2] C. Mukhopadhyay, "A nested framework for transparency in public private partnerships: case studies in highway development projects in India," Progress in Planning, vol. 107, pp. 1-36, July 2016.

[3] R. Whitaker, "The end of privacy: how total surveillance is becoming a reality (large print 16pt)," ReadHowYouWant.com, 2010, pp. 328.

[4] J.S. Coleman, "Social capital in the creation of human capital," The American Journal of Sociology, Supplement: Organizations and institutions: sociological and economic approaches to the analysis of social structure, 1998 , vol. 94, pp. S95-S120.

[5] C. Hood and D. Heald, "Transparency: the key to better governance?" Proceedings of the British Academy 135, Oxford: Oxford University Press, 2006, pp. 246.

[6] L. Boronina, D. Ronzhina, and Z. Senuk, "Evaluating the effectiveness of socially-oriented non-profit organizations social projects: approaches and methods," 9th international days of statistics and economics, Prague, pp. 209-219, 2015.

[7] Project Management Body of Knowledge. 5th ed., Project Management Institute, Campus Boulevard Newtown Square, 2013, pp. 790.

[8] M. Belykh, "PRINCE2 is in the lead among the methods of project management: the results of the study The Axelos PPM Benchmark study - 2017,” (М. Белых, “PRINCE2 лидирует среди методов проектного управления: результаты исследования The Axelos PPM Benchmark study - 2017") [Web resource] Retrieved from URL: https://www.pmservices.ru/project-management-news/prince2-lidiruetsredi-metodov-proektnogo-upravleniya-rezultaty-issledovaniya-theaxelos-ppm-benchmark-study-2017/.

[9] Resistance to changes, IPMA Research Management Board, unpublished documentation, Istanbul, 2007

[10] J. Betta and J. Jastrzębska, "Management of research projects - lessons learned," Proceedings of CBU International Conference on Innovations Science and Education, Prague, pp. 39-44, 2017.

[11] Manifesto for Agile Software Development, [Web resource] Retrieved from URL: http://agilemanifesto.org.I.S. Jacobs and C.P. Bean, "Fine particles, thin films and exchange anisotropy," in Magnetism, G.T. Rado and H. Suhl, Eds. New York: Academic, 1963, , vol. III, pp. 271-350.

[12] K. Schwaber and J. Sutherland, "Scrum guide, the definitive guide to scrum: the rules of the game," [Web resource] Retrieved from URL: https://www.scrumguides.org/docs/scrumguide/v2017/2017-ScrumGuide-US.pdf\#zoom=100.

[13] Extreme Programming (Metodyka Extreme Programming), [Web resource] Retrieved from URL: https://mfiles.pl/pl/index.php/Metodyka_Extreme_Programming.

[14] M. McLaughlin, "What Is Agile Methodology?" [Web resource] Retrieved from URL: https://www.versionone.com/agile-101/agilemethodologies/. 
[15] M. Niazi, S. Mahmood, M. Alshayeb, A. M. Qureshi, K. Faisal, and N. Cerpa, "Toward successful project management in global software development," International Journal of Project Management, vol. 34, pp. 1553-1567, 2016.
[16] A. Riveraa and J. Kashiwagi, "Identifying the State of the Project Management Profession," Procedia Engineering, vol. 145, pp. 13861393, 2016.

[17] D. Nedbal, A. Auinger, and A. Hochmeier, "Addressing transparency, communication and participation in Enterprise 2.0 projects," Procedia Technology, vol. 9, pp. 676-686, 2013. 